\title{
ARTERIO-VENOUS ANEURYSM OF THE LUNG
}

\author{
BY \\ C. G. BARNES, L. FATTI, AND D. M. PRYCE \\ From Hillingdon Hospital, Middlesex, and St. Mary's Hospital, London
}

Arterio-venous aneurysm of the lung is usually considered to be a rare lesion, and by 1942 only four examples were on record. During the last six years, however, nineteen more cases have been published, and it is likely that as the clinical features of this syndrome become better known still more of these patients will be separated from the cases of cyanotic congenital heart disease and polycythaemia rubra vera with which they are often confused. Although the lesion has been described by some writers as a cavernous haemangioma, we believe, for reasons discussed below, that it is an arterio-venous aneurysm and not a true vascular tumour.

The presence of the arterio-venous aneurysm causes a proportion of the venous blood in the pulmonary artery to be shunted directly into the pulmonary vein without passage through the lung capillaries. Venous blood returns to the left side of the heart to mix with the arterial blood of the systemic circuit and thus to cause cyanosis, dyspnoea, and compensatory polycythaemia. The aneurysm may bring about the patient's death through haemoptysis, or cause dyspnoea which is incapacitating.

Hepburn and Dauphinee (1942) were the first successfully to excise an arterio-venous aneurysm of the lung, and in the same year Shenstone's patient was cured by pneumonectomy. Since that time removal of the aneurysm either by lobectomy, or by local resection when the lesion is multiple (Janes, 1944), has become the accepted method of treatment, and with the recent advances made in the technique of thoracic surgery excellent results are to be expected. In this paper we report the case histories of two patients with arteriovenous aneurysms of the lung, and proceed to discuss the pathology of these "tumours" and the characteristic clinical picture to which they give rise.

\section{CASe Reports}

Case 1.-A woman, aged 17 years, had been normal at birth, and cyanosis was first noticed at the age of 3 years. This rapidly deepened a year later after an attack of whooping-cough during which she had haemoptysis. At that time she was diagnosed as suffering from congenital heart disease. By the age of 12 clubbing of the fingers had appeared, and in a radiograph of the chest a shadow was seen in the upper lobe of the left lung. She was still considered to have congenital heart disease and was not allowed to play games at school. About the age of 15 she became increasingly breathless on exertion, and had several attacks of unconsciousness lasting about 10 minutes and accompanied by clonic convulsions. In 1946 she was diagnosed as having an arterio-venous fistula in the lung by Dr. Hewart Bell, who referred the patient to us.

On examination she was found to be a normally developed girl, grossly cyanosed, with clubbing of the fingers and toes. The heart was not enlarged; the heart sounds were normal, the rhythm was regular, and the blood pressure was $118 / 85 \mathrm{~mm}$. $\mathrm{Hg}$. A rough systolic murmur was audible in the third left interspace anteriorly ; this murmur, whose point of maximum intensity lay just internal to the anterior axillary line, became louder during inspiration, when a diastolic continuation could be made out. No other abnormality could be found in any system of the body, and there were no haemangiomata of the skin or mucous membranes.

Radiography showed the heart to be normal in size and contour. The lung fields were not congested, but in the middle zone of the left lung there was a wellmarked opacity connected by a further band of opacity to the hilar shadow. In the lateral view this opacity was localized to the superior branch of the lingular segment of the left upper lobe bronchus (Plate VII $a$ and $b$ ). Radioscopy showed systolic pulsation in the tumour and this was proved by kymography, while a tomograph confirmed that the tumour was connected by a leash of vessels to the hilum of the lung (Plate VIIc).

A blood count showed 7.8 million red cells per c.mm. of blood, white cells 6,800 per c.mm., and haemoglobin $22 \mathrm{~g}$. per $100 \mathrm{ml}$. The arm to tongue circulation time (saccharin) was 13 seconds, with a single end point. The diagnosis of arterio-venous aneurysm within the lung, with secondary polycythaemia, was thus confirmed.

A thoracotomy was carried out on Sept. 12, 1946; under pentothal, cyclopropane, and oxygen anaesthesia. The tumour, 3 in. in diameter, lay just beneath the surface of the lung, pulsating vigorously, 


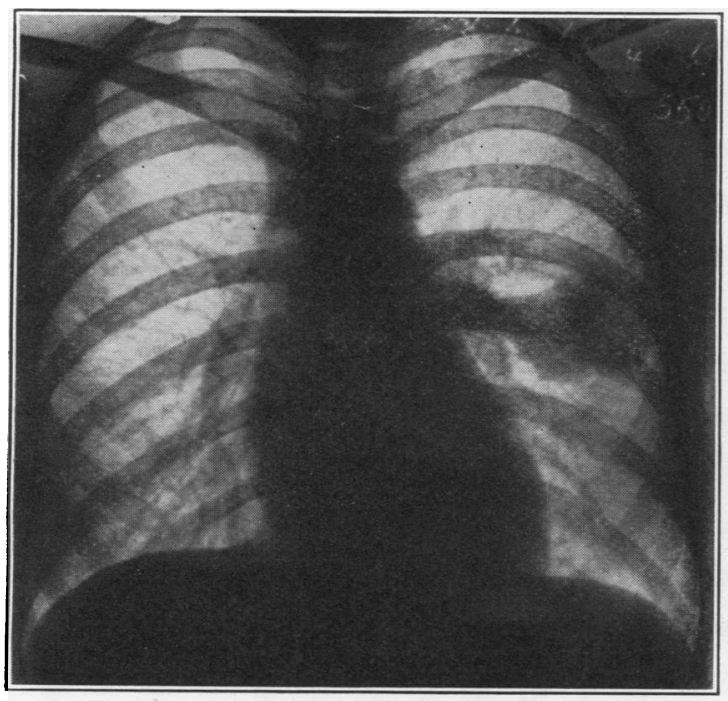

(a)

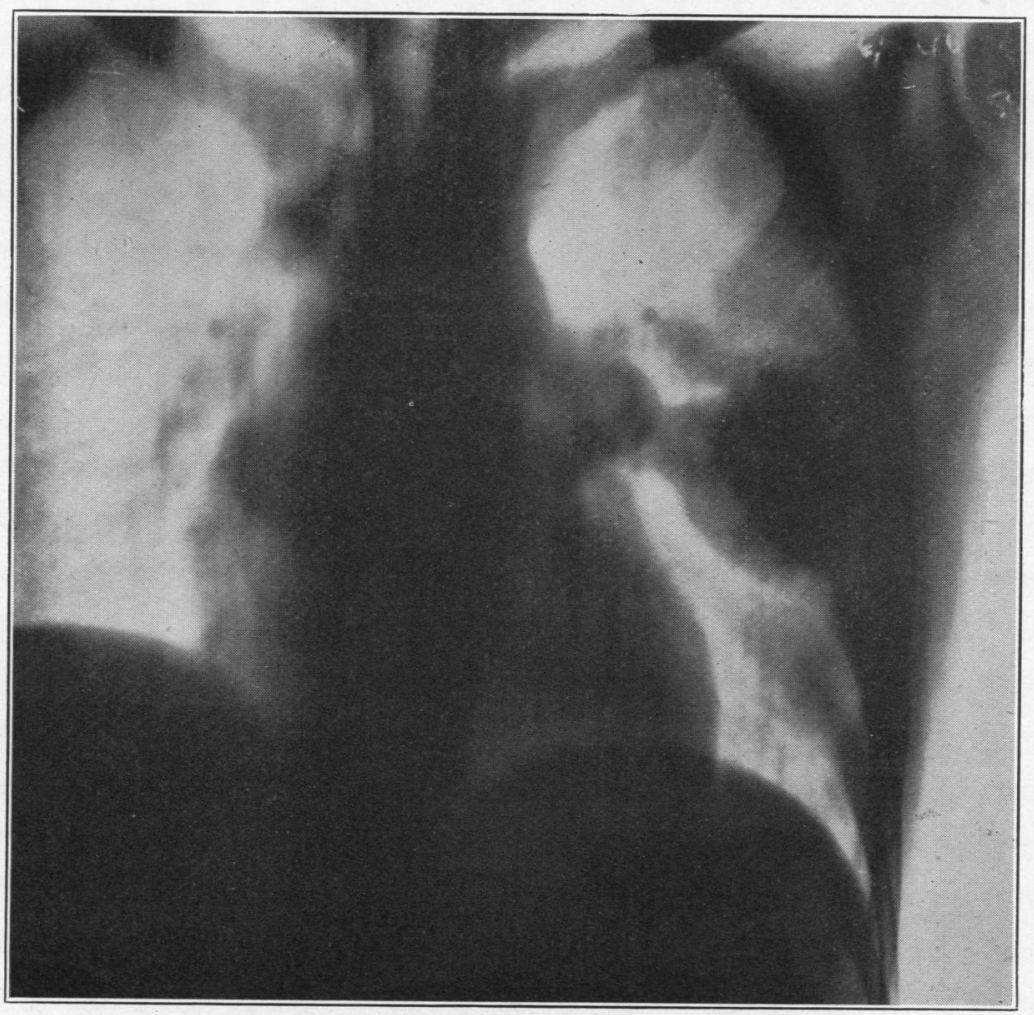

(c)

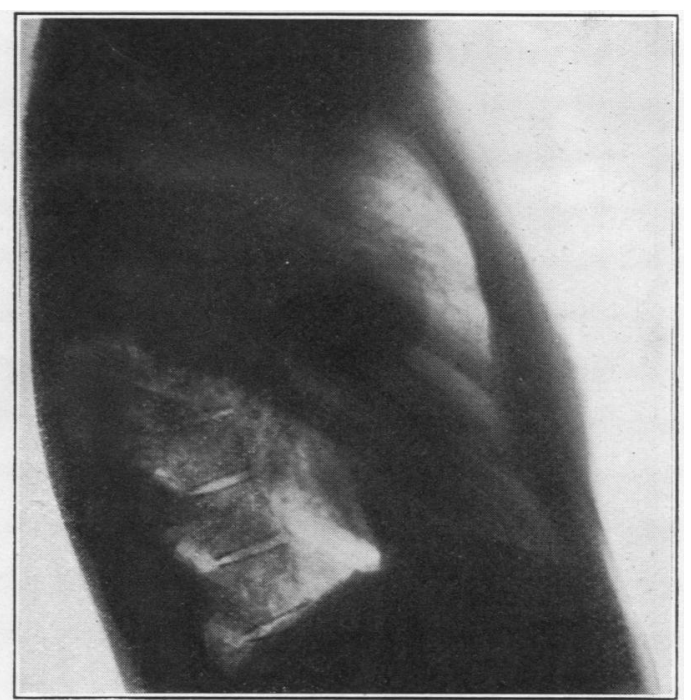

(b)

Plate VII $(a)$ and $(b)$.-Case 1 : radiograph showing aneurysm in left upper lobe. $(c)$.-Case $1:$ tomograph showing vessels entering aneurysm from the hilum. 


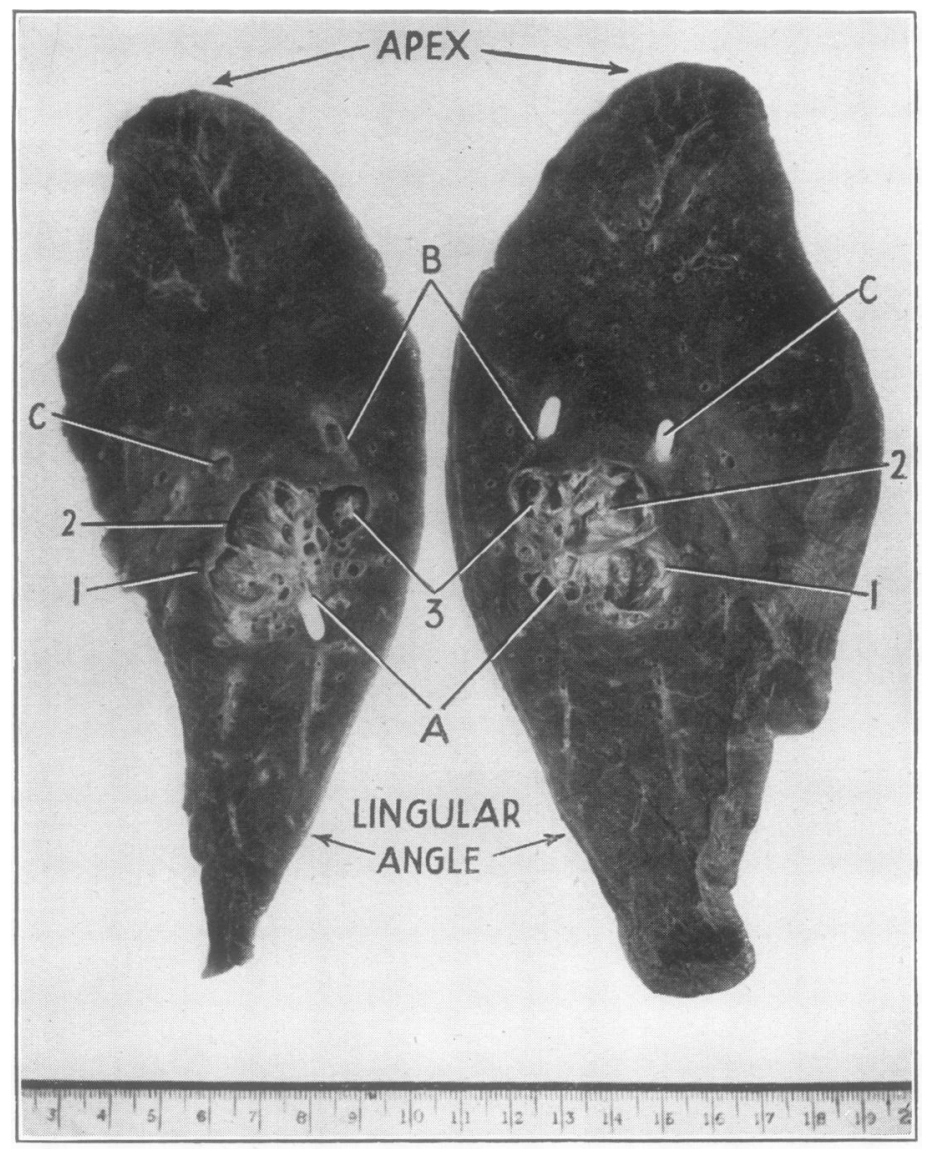

Plate VIII (a).-Case 1 : opposing surfaces of paramedian section of left upper lobe. The three dilated arteries which enter the cavity are lettered A, B, and C and indicated by blunt probes. The numbers refer to the three large venous spaces of the cavity, and the arrows are retrograde in the connected veins. (b). Case 1: aneurysm filled with lipiodol, showing that it consists essentially of one cavity.

(a)

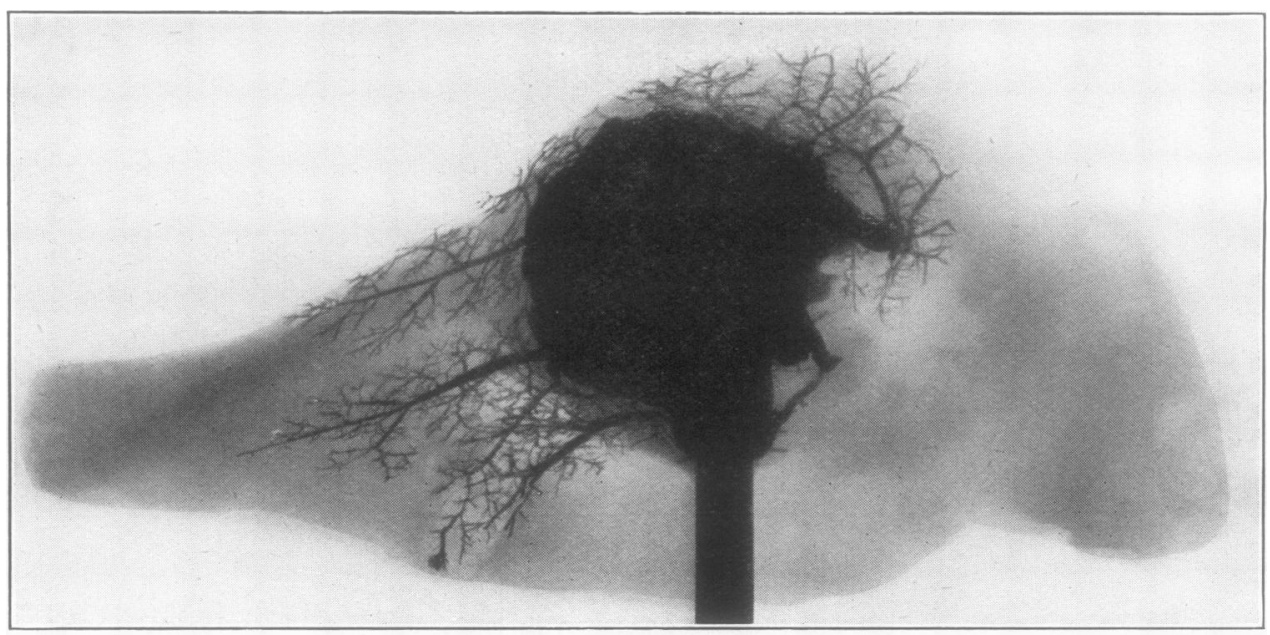

(b) 


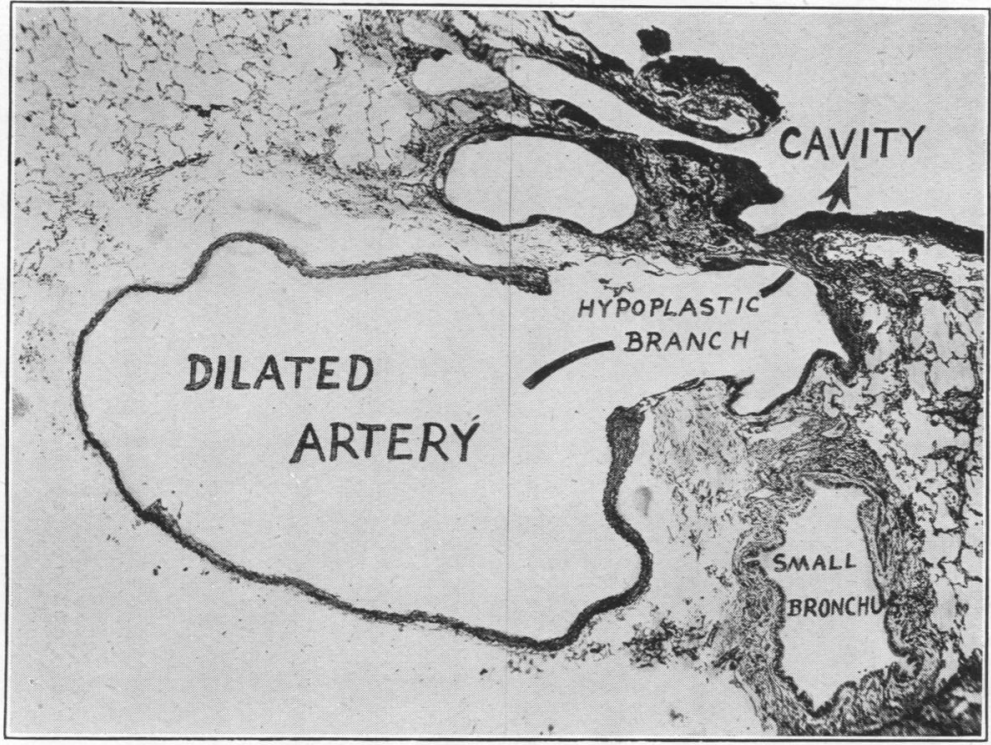

(a)

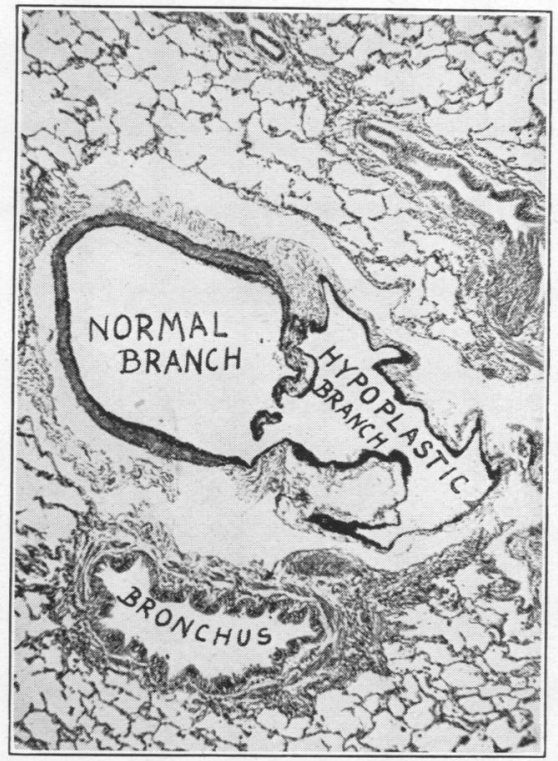

(b)

Plate IX (a).-Case 1: dilated thin-walled elastic artery 5 with hypoplastic channel by which it communicated with the aneurysm. In places the wall of this branch consists of only one elastic lamina. (b).-Case 1 : bifurcating pulmonary artery near the cavity. One division is normal ; the other, which entered the cavity, is hypoplastic. 


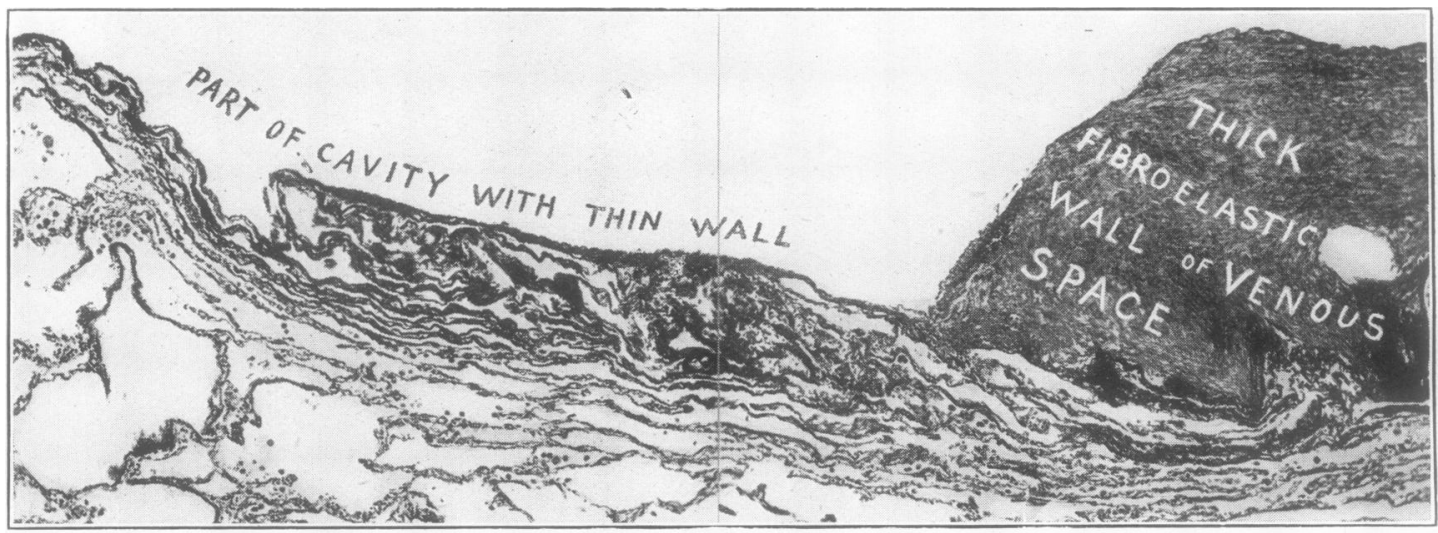

(a)

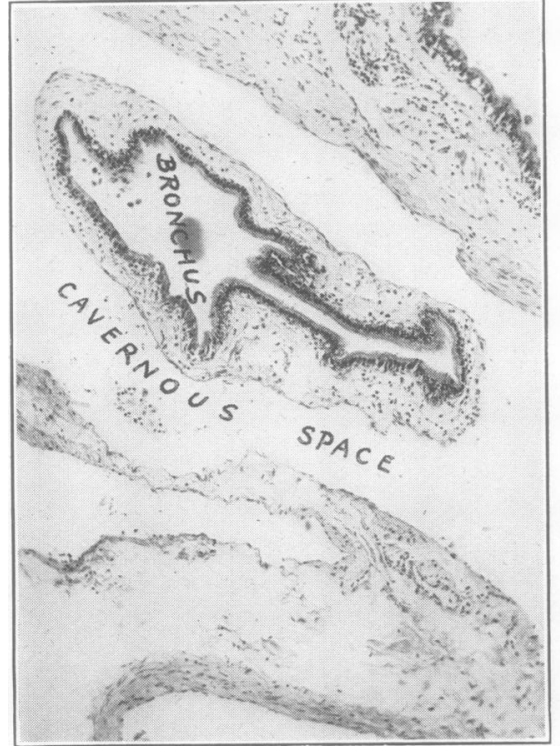

(b)

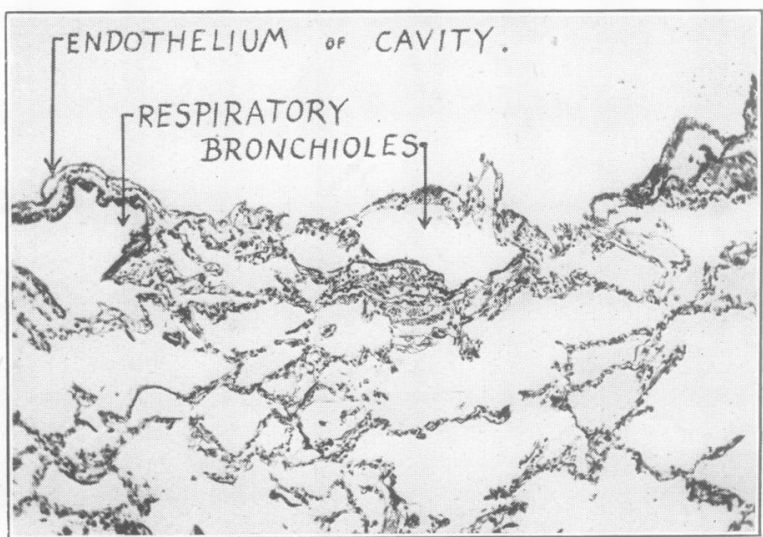

(c)

Plate X (a).-Case 1 : section through venous space to show variation in the thickness of its wall. Note the slight alveolar compression. (b).-Case 1 : bronchus traversing the cavity of the aneurysm. (c).-Case 1 : aerated lung alongside cavity where the wall consists of endothelium only. 

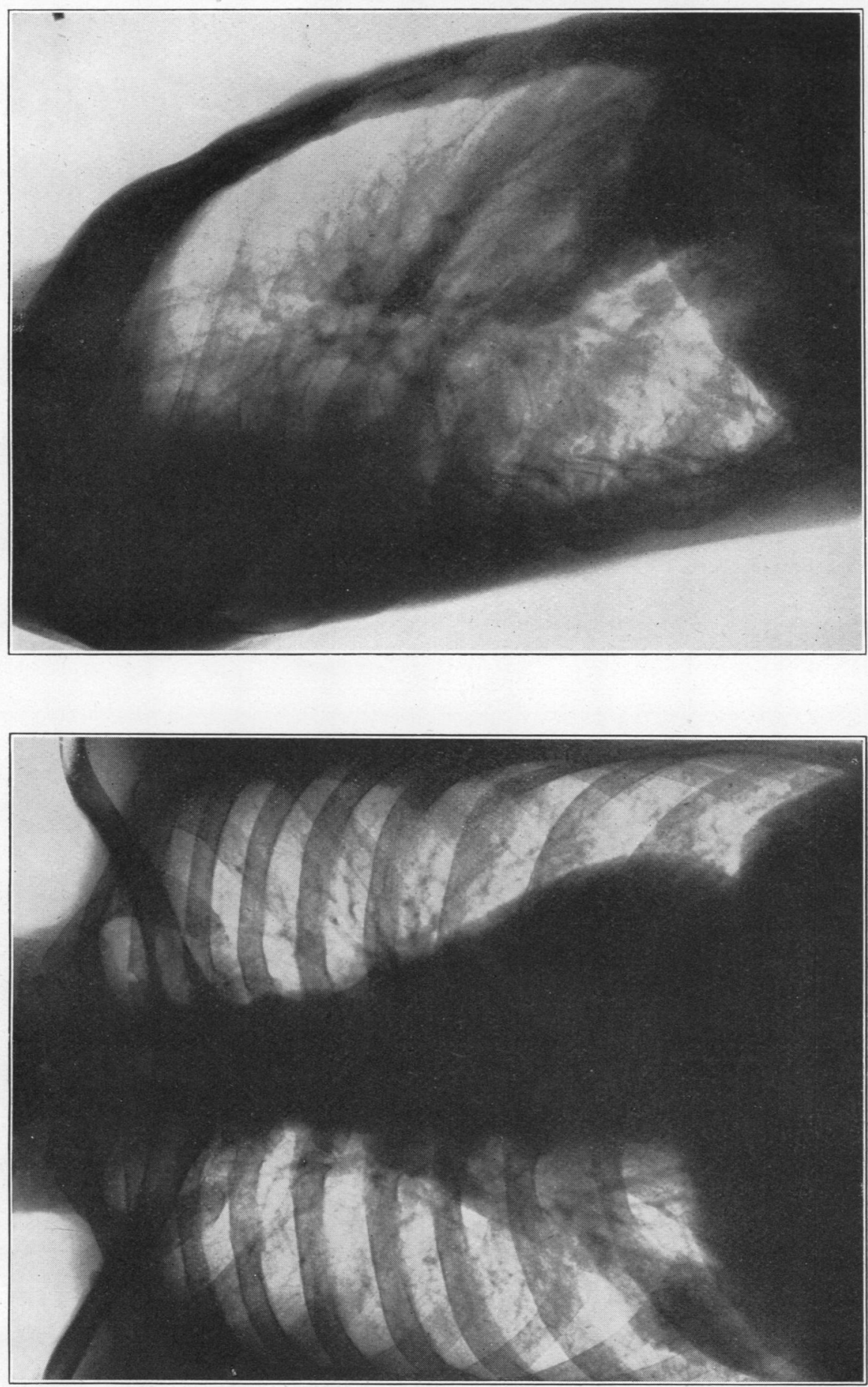

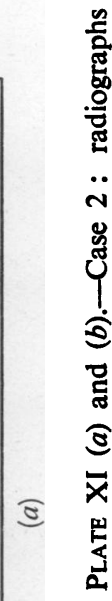




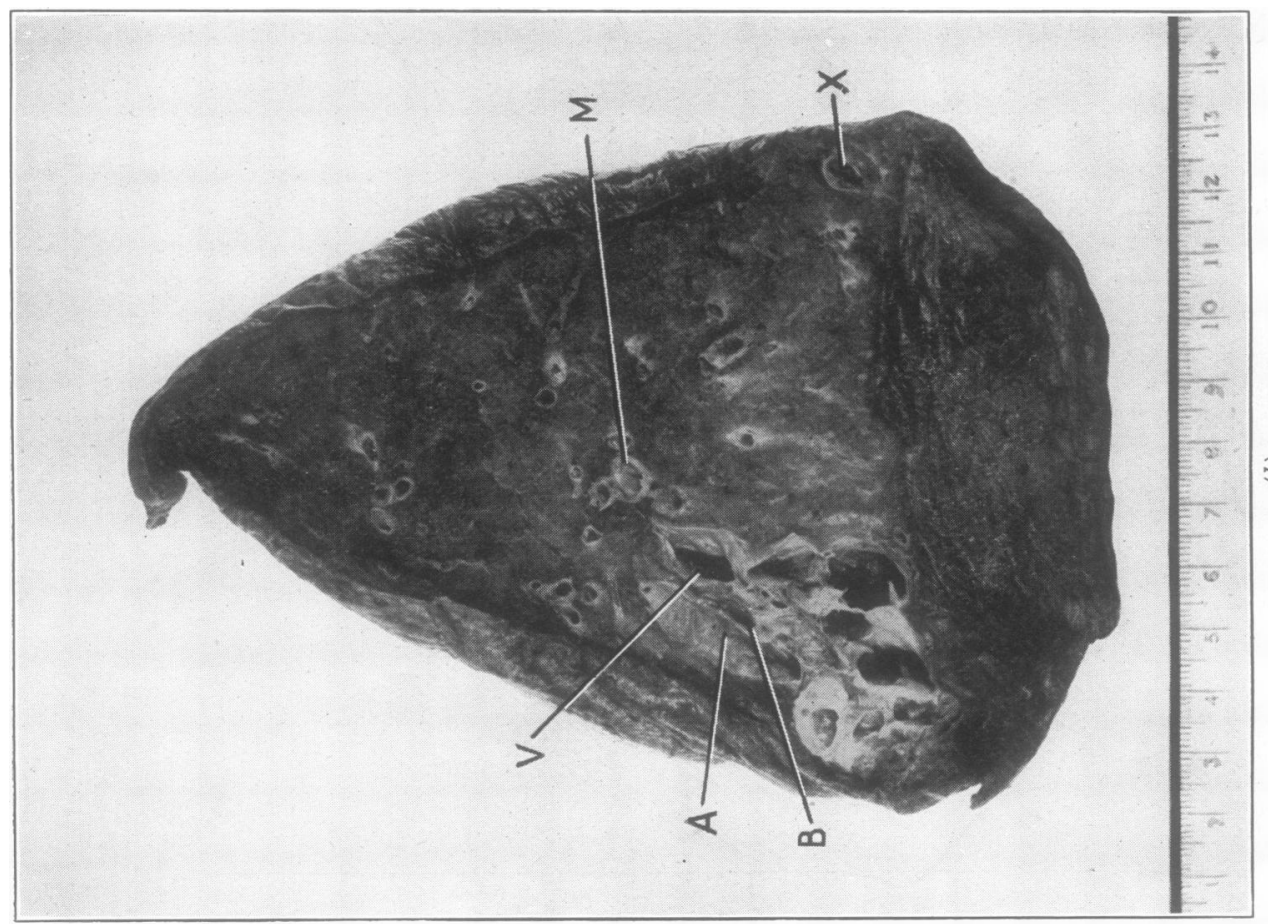

哥兽

2

$\ddot{\sim} \ddot{्}$

实

论造

宅宗

2

तิ

政.

- 已্ర

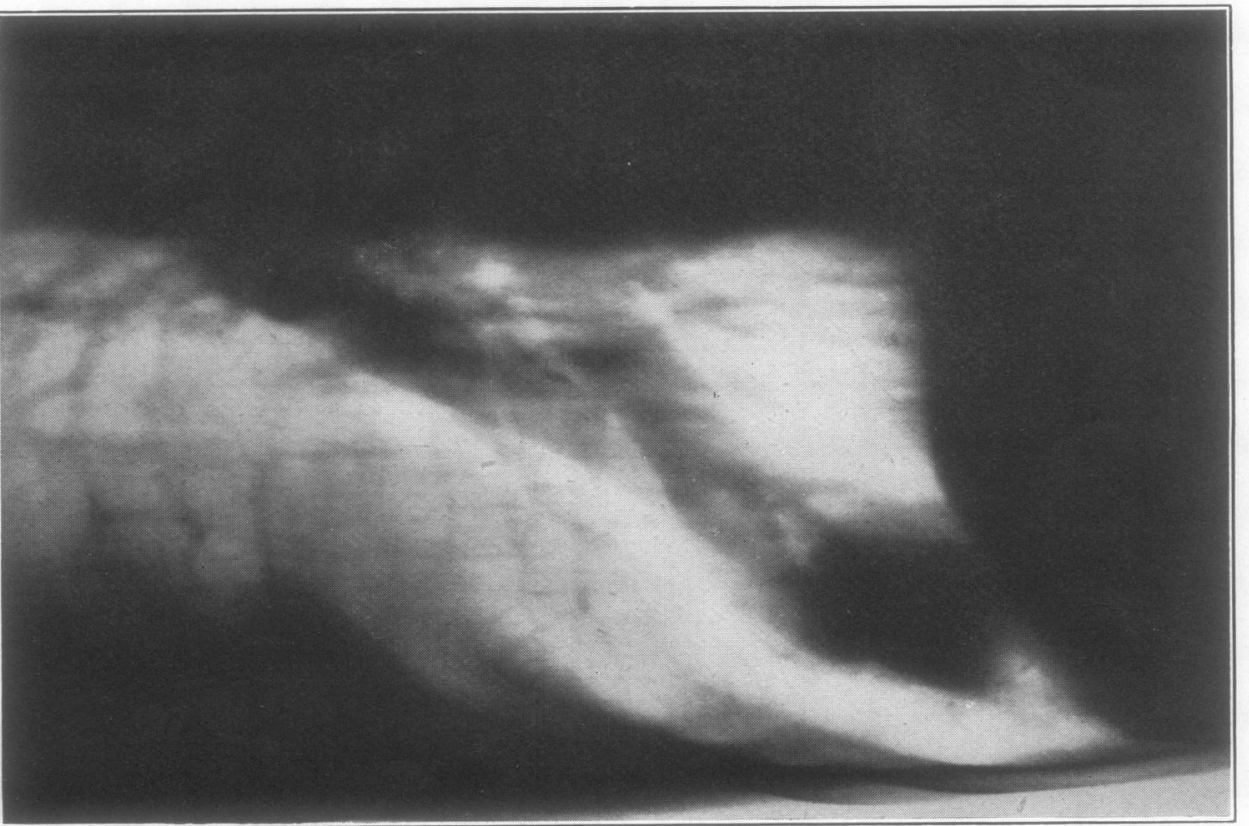


and a marked systolic thrill was felt when the mass was handled. Only one aneurysm was present, and a leash of three thin-walled vessels radiated out from the left pulmonary artery to enter the tumour. Left upper-lobe lobectomy was performed by individual dissection; the operation was straightforward. The day after the operation the patient developed a fulminating tracheo-bronchitis due to infection with a penicillin-insensitive staphylococcus, the origin of which we were unable to trace. Staphylococcal bronchopneumonia followed, and the patient died forty-eight hours later. Autopsy confirmed the cause of death; the heart was not hypertrophied and no other abnormality was found in any organ of the body.

Pathology.-The specimen consisted of the upper lobe of the left lung, on the lateral aspect of which there was a puckered area where the pleura was domed. Deep to this there was a cavity ( 3 by 2 by $2 \mathrm{~cm}$.) mainly in the lateral division of the lingular sector (Plate VIII a). The cavity had a smooth bluish lining, was partly divided by septa and trabeculae, and communicated with the branches of five large, thin-walled vessels (three arteries and two veins). One artery (A, Plate VIII $a$ ), accompanied the lateral division of the lingular bronchus, while the other two (B and C) accompanied branches of the antero-lateral and apico-posterior bronchi. The larger vein, which entered the ventral part of the hilum, received two tributaries which funnelled out into two of the three main compartments of the cavity (compartments 1 and 2 of Plate VIII $a$ ). The smaller vein, which drained the third large compartment, went to the dorsal part of the hilum. Radiopaque oil injected through one of the larger veins completely filled the cavity (Plate VIIIb).

Microscopical examination showed the thin walls of the dilated arteries to have the compact elastic lamination of pulmonary arteries. In the vicinity of the cavity the walls of the hypoplastic arteries became still more attenuated, and they were reduced in some areas to a single elastic lamina (Plate IX $a$ ). The attenuation was sometimes abrupt, and was in places associated with branching (Plate IX $b$ ). The venous spaces in most parts had thick fibro-elastic walls, but in some parts the walls were reduced to little more than endothelium (Plate $\mathrm{X} a$ ). Tributary venules from the adjacent lung entered the venous loculi. Some extensions of the cavity surrounded bronchi (Plate $\mathrm{X} b$ ). The smaller arteries and veins in the lung, away from the cavity, were frequently hypoplastic and ectatic. In places the lung adjacent to the cavity was compressed (Plate $\mathrm{Xa}$ ), but even where the lung was covered only by endothelium this was not marked and was sometimes absent (Plate $\mathrm{Xc}$ ). There was some chronic pneumonitis.

Case 2.-A man, aged 42 years, had been perfectly normal as a child, was a fine athlete as a young man, and was accepted for life insurance at the age of 24 without comment or loading. Two years later he was noticed to be cyanosed after a vigorous game of hockey, and a doctor who examined him said that he had congenital heart disease. From that time cyanosis steadily increased, and clubbing was first noticed at the age of 31 . In 1941, when 36 years old, he worked as a member of a first-aid squad, became increasingly breathless, and developed a cough with an occasional streak of blood in the sputum. At the end of 1941 he had a large haemoptysis, and from then until 1946, when we first saw him, he had seven haemoptyses, in the worst of which he coughed up $10 \mathrm{oz}$. of blood. In 1942 a radiograph of his chest was taken at another hospital, and he was told that he had a "spot on one of the lungs," but no further action was taken and we have been unable to trace the films. His exercise tolerance steadily deteriorated until by 1946 he could walk only very slowly.

On examination the patient was intensely cyanotic with gross clubbing of the fingers and toes; he had telangiectases on the face. The mucous membranes were almost black, and it was only on close examination that one could make out numerous small haemangiomata on the lips. No other members of his family had such tumours so far as he was aware. There were no physical signs in the heart or lungs, no murmurs were heard, the blood pressure was 110 / $70 \mathrm{~mm}$. $\mathrm{Hg}$, and the tip of the spleen was just palpable. The vital capacity was $2,900 \mathrm{ml}$.

A blood count showed 9.5 million red cells per c.mm. of blood, and leucocytes 6,300. The haemoglobin was $23.6 \mathrm{~g}$. per cent, the haematocrit reading 78 per cent, the total circulating b.ood volume 6.6 litres (equivalent to $113 \mathrm{ml}$. per $\mathrm{kg}$. of body weight), and blood viscosity index 52 . The arm to tongue circulation time (saccharin) was 24 seconds with a single end point.

Radiography showed a large tumour lying in the lower zone of the right lung and apparently connected to the hilum by a leash of vessels (Plate XI). The lateral view showed the mass to be situated centrally in the anterior basic segment of the right lower-lobe bronchus. The rest of the lung fields were clear and the heart normal in size and contour. On radioscopy slight systolic pulsation could be observed in the tumour, but kymography did not confirm this. A series of tomograms revealed two large vessels, an artery and a vein, connecting the tumour to the hilum (Plate XII $a$ ), and confirmed the clinical diagnosis of arterio-venous aneurysm of the lung. Radiographs of the hands showed no subperiosteal new bone formation. Even after the tumour had been localized radiographically no bruit could be heard over it on auscultation. The electrocardiogram showed right axis deviation but was otherwise normal.

Right lower- and middle-lobe lobectomy was carried out on May 7, 1947, under pentothal, cyclopropane, and oxygen anaesthesia. The lung was free except in the costo-phrenic angle overlying a tumour in the right lower lobe. At this point there were thick adhesions of long standing, suggesting that there had been 
some inflammatory lesion in the underlying lung. The tumour was about 2 inches in diameter, with a wellmarked systolic thrill and expansile pulsation. It was soft and easily compressed, and presented on the diaphragmatic surface of the right lower lobe near its axillary border. A large pulmonary artery could be felt entering the tumour, but the pulmonary vein was normal in size and its pulsation diminished as soon as the artery was tied. Right middle- and lowerlobe lobectomy was performed by individual dissection, as it was found that the lower pulmonary vein drained the middle lobe in addicion to the lower. A minor congenital anomaly was that the artery to the middle lobe arose from the pectoral branch of the vessel to the upper lobe.

Convalescence was stormy, being complicated by an empyema which contained at first Pfeiffer's bacillus and later Ps. pyocyaneus; a bronchial fistula formed and drainage by rib resection was instituted. The remaining lobe took two months to expand and fill the hemithorax, the fistula closing spontaneously. Cyanosis had practically disappeared by the end of the first week, when the red cells were $6,400,000$ per c.mm. of blood and the haemoglobin $20.3 \mathrm{~g}$. per cent. Ten days later the count was 5,470,000 and the haemoglobin $16.5 \mathrm{~g}$. per cent. Ultimate recovery was not perfect, for the patient has a persistent sinus and his exercise tolerance is not yet normal for his physique. Six months after the operation clubbing had regressed.

Pathology.-The specinen consisted of the middle and lower lobes of the right lung, the general shape and size of which were normal. In the anterior part of the base of the lower lobe there was a large cavernous lesion $3 \frac{1}{2}$ by 2 by $2 \mathrm{~cm}$. which was enveloped by lung tissue except inferiorly, where it reached the pleura (Plate XII $b$ ). There was little macroscopic evidence of compression of the lung tissue, and the p'eura over the lesion was only slightly domed. The cavity had a smooth lining, and was divided by trabeculae and fenestrated septa into inter-communicating spaces, the largest of which (as in Case 1) were venous. These spaces were the direct continuation of the branches of three large blood vessels, which, by their anatomical disposition, were easily recognized as a vein and two arteries. The vessel V (Plate XII $b$ ) formed the main tributary of the infra-hilar vein. The vessel $A$ was the main branch of the artery to the lower lobe, and accompanied the anterior basal bronchus, while the vessel $M$ was the artery accompanying the middle basal bronchus. These three vessels were very greatly dilated (up to $0.7 \mathrm{~cm}$. diameter), and thin-walled. In other parts of the lung the arteries were of normal size and thickness, but serial sectioning revealed that many of them were extremely thin at the points where they branched. The veins were hypoplastic and slightly dilated. One vein (X in Plate XII $b$ ) was also elongated and kinked. In places the intima of this vein showed fibro-elastic thickening, but in one part the wall consisted of little more than endothelium. The peripheral arterioles and venules we:e often hypoplastic and dilated. There were a few widely scattered iron-containing histiocytes, probably associated with the haemoptyses. The bronchi were chronically inflamed but there was no $\bar{S}$ bronchiectasis. The alveolar passages were emphy- $\mathbb{\Phi}$ sematous.

\section{Discussion}

With the addition of these two patients, $25 \overrightarrow{\vec{\omega}}$ examples of arterio-venous aneurysm of the lung are now on record. Seven more cases were men- $\overrightarrow{\vec{x}}$ tioned briefly in the discussion which followed $\dot{\omega}$ the presentation of the paper by Maier and his $\omega$ colleagues (1948), but these are not included in the present survey. A most characteristic clin:cal picture emerges from the case histories, although some of the reports have been brief or incomplete. Of the twenty-five patients, nine have been female and sixteen male.

SYMPTOMATOLOGY.-The outstanding feature of $\frac{7}{3}$ this syndrome is the intense cyanosis, which has $\mathbb{D}$ been absent only in Whitaker's (1947) second case, and in that described by Duvoir and his colleagues $\stackrel{\infty}{\infty}$ (1939), in both of which the tumour was small and the arterio-venous shunt correspondingly slight. In nine patients the cyanosis had been present in some degree since birth, but in the remainder it developed either in childhood (on three occasions after an acute respiratory infection) or else during early adult life. Once manifest, cyanosis gradually deepens, with accentuation during exercise, until in the course of years the degree of cyanosis in these patients is comparable with that seen in severe examples of Faliot's tetralogy. Three factors are probably responsible for the patients' colour-the arterio-venous shunt through the aneurysm which allows venous blood to enter the systemic circulation, the compensatory polycythaemia, as a result of which the blood contains a large amount of reduced haemoglob: $n$, and the peripheral vasodilatation which accompanies the increase in blood volume. This last feature may be responsible in part for the clubbing of the fingers and toes which develops soon after the cyanosis has become evident, and for the fact that a raised blood pressure has never been recorded in these patients despite the large circulating blood vo'ume.

Increasing dyspnoea on exertion is the second symptom of which these patients complain, and which eventually incapacitates them. It develops later than the cyanosis; but like that symptom it is steadily progressive, and it appears to be due to stimulation of the respiratory centre by the high carbon-dioxide content of the arterial blood which was demonstrated by Maier and others (1948) and also to stimulation of the sino-aortic chemorecep- 
tors by the anoxaemia which is a marked feature in these patients (Hepburn and Dauphinee, 1942 ; Maier and others, 1948). Certainly it is not due to pulmonary congestion, for it is remarkable that heart failure has never occurred during the course of this syndrome in spite of the pulmonary arterio-venous shunt, which must greatly increase the venous return to the left auricle and so augment the output of the heart and the work of the left ventricle. All observers are agreed that the general lung fields are not congested, and that there is no systemic venous engorgement ; and no cardiac enlargement has been recorded except for slight hypertrophy- of the left ventricle in Alexander's (1945) case and Lindgren's (1946) first patient, in whom mitral stenosis was also present. Absence of cardiac embarrassment is in striking contrast to the enlargement and ultimate failure of the heart which follows the development of an acquired arterio-venous fistula in the systemic circuit. In systemic cases, however, the arteriovenous fall in blood pressure across the aneurysm is much greater than in the pulmonary circuit, and the venous return correspondingly larger.

Cerebral anoxaemia is usually also held responsible for the transient attacks of faintness, vertigo, or convulsions which have occurred in nine patients, usually after exertion, for similar symptoms may also be present in persons with cyanotic congenital heart disease. 'Lindgren, whose second patient had such episodes, has made the alternative suggestion that they are due to cerebral air embolism, but gives little evidence to support this theory.

In addition to these symptoms, haemorrhage may cause these patients to seek advice, for haemoptysis occurred in seven in this series, and caused the death of Rodes' (1938) patient, whilst the infant reported by Bowers (1936) died from rupture of the haemangioma into the pleural cavity. Repeated epistaxis took place in six patients from rupture of capillary haemangioma on the nasal septum, and such tumours have been noticed on the lips, tongue, septum, or eyelid in eleven patients. Capillary haemangiomata of the skin or mucous membranes so frequently accompany pulmonary arterio-venous aneurysm that they have diagnostic value and should always be sought ; in Cleland's (1948) patient an haemangioma was found in the liver at autopsy. These small tumours may be found in the patients' relatives; this was so with four patients, and in two others there was presumptive evidence of their presence in other members of the family. There is no record of arterio-venous aneurysm of the lung being present in more than one generation, but Goldman (1947) has briefly recorded the lesion in two brothers.

Clinical Features.-The presence of an arterio-venous shunt in the pulmonary circuit may sometimes interfere with physical development, for in the records of four patients (three of whom had been cyanotic since birth) it is stated that they were " frail," " asthenic," or " never robust."

The cyanosis and clubbing have already been mentioned and are so striking that one immediately thinks of congenital heart disease if the patient is a child, or of polycythaemia rubra vera if an adult. Although clubbing may be gross, osteo-arthropathy, with new bone formation beneath the periosteum, has only been recorded once (Adams and others, 1944).

Examination of the heart reveals no abnormality, the blood pressure is normal, and the electrocardiogram is either physiological, or shows slight right axis deviation without evidence of ventricular strain. The lungs are normal unless the aneurysm is large and situated near the costal surface of the lung, in which case a systolic murmur may be heard over it, sometimes continuing into diastole. This murmur, which may increase in intensity during inspiration (Jones and Thompson, 1944) or may be heard only at that time, is an important physical sign and has been found in twelve of the twenty-five reported cases. Occasionally its presence may cause some confusion, as in our first patient, when the quality and site of the murmur so closely simulated that of a patent ductus arteriosus that a complicated congenital heart lesion was at first suspected. With one exception, the vital capacity when recorded has been normal. Capillary haemangiomata of the skin or mucous membranes may be present, but if cyanosis is very deep they are not easily seen and may be recognized only after the cyanosis has been cured by lobectomy.

Further physical examination reveals no abnormality, but the absence of splenic enlargement is important and may be the first feature to throw doubt on a clinical diagnosis of polycythaemia rubra vera. In our second case and in Goldman's (1943) the tip of the spleen was palpable, but apart from these splenic enlargement has not been reported.

The arterio-venous shunt leads to remarkable circulatory, adjustments with a great increase in blood volume due mainly to polycythaemia. Thus in the case of Adams and his colleagues the circulating blood volume was $12,750 \mathrm{ml}$. with a haematocrit reading of 82 per cent, whilst in that of Hepburn and Dauphinee the erythrocyte count 
was 9.6 million per ml., haematocrit 80 per cent and the haemoglobin $22.8 \mathrm{~g}$. per cent-values similar to those found in our second patient. As would be expected with a compensatory polycythaemia, the leucocyte count is never raised and primitive white cells are not seen in the circulating blood. When the oxygen saturation of the arterial blood has been estimated it has been found to be greatly diminished, for example, 70 per cent in the case of Hepburn and Dauphinee and 59 per cent after exertion in the patient reported by Maier and others. The arm-to-tongue circulation time was normal in Goldman's (1943) and Cleland's (1948) cases and also in our first patient, but Makler and Zion (1946) found it to be 20 seconds, and in our second patient it was 24 seconds ; in no case has a double end point to the test been observed. Any diminution in the rate of circulation is probably due to the increase in blood viscosity, which was 10 times the normal in our second case.

RADIOGRAPHY.-A radiograph shows the heart to be of normal size and contour and the lung fields clear except for the shadow caused by the lesion itself, which in five cases has been multiple ; in Lindgren's second case five tumours were present. The aneurysm appears as a circumscribed opacity without surrounding inflammatory reaction, and may be connected to the hilum by a leash of vessels. On radioscopy the aneurysm may pulsate, as in our first case when this was confirmed by kymography, and it may be observed to decrease in size on the patient attempting forced expiration with a closed glottis (Valsalva's experiment), or to increase in size when the patient tries forced inspiration with mouth and nose closed (Lindgren, 1946). Tomography is of the greatest value, as has been emphasized by several writers; with its aid large vessels may be made out running between the tumour and the hilum (Plates VII $b$ and $\mathrm{XII} a$ ) and the diagnosis put beyond doubt.

Differential Diagnosis.-There are four conditions with which pulmonary arterio-venous aneurysm may be confused-cyanotic congenital heart disease, Osler-Vacquez disease (polycythaemia rubra vera), bronchiectasis, and pulmonary tuberculosis.

In childhood, arterio-venous aneurysm of the lung may at first suggest congenital heart disease on account of the cyanosis, clubbing, polycythaemia and diminuation of exercise tolerance. The absence of unusual physical signs in the heart on clinical examination with the normal cardiac contour on radioscopy, when the tumour itself is as a rule easily seen in the lung fields, soon make the true diagnosis clear. Without radioscopy the case might well be classed as cyanotic congenital heart disease and treatment omitted, but with the great interest now being taken in congenital heart disease, especially since Blalock introduced his operation for pulmonary stenosis, few cases are likely to escape full examination.

In adults, arterio-venous aneurysm of the lung may be mistaken for polycythaemia rubra vera on account of the gradual progress of the cyanosis and polycythaemia and the striking appearance of the patient. Smith and Horton's case (1939) was treated with phenyl hydrazine for a long period before coming under their care, whilst Goldman's (1943) patient, who was originally thought to have congenital heart disease, was later diagnosed as polycythaemia rubra vera and treated with radio-active phosphorus before the true state was realized. The absence of splenic enlargement should raise serious doubts of the accuracy of a diagnosis of Osler-Vacquez disease, whilst the normal white cell count in spite of the polycythaemia suggests that the latter is compensatory and not the primary disease. Radioscopy, with visualization of the tumour and its vascular pedicle confirmed by tomography or angiography, will establish the correct diagnosis. Hirsch (1936) described radiological opacities in the lungs of patients with polycythaemia rubra vera, without associated infiltration around them. He believed these to be due to small thromboses or haemorrhages, and described how they rapidly reached a certain density and disappeared leaving no trace. It seems certain that his patients were examples of true Osler-Vacquez disease, and not of polycythaemia accompanying arterio-venous aneurysm of the lung.

The association of haemoptysis with cyanosis and clubbing may at first suggest bronchiectasis or lung abscess, but the cyanosis and polycythaemia are usually excessive for such a diagnosis, and the absence of relevant history of lung disease or of expectoration makes such an aetiology unlikely. It has already been emphasized that the radiological appearances do not suggest an inflammatory lesion, but in doubtful cases the tomograms will reveal the typical enlarged vessels running from the lesion to the hilum and at once suggest the true pathology, whilst angiography will prove that the lesion is vascular.

When the aneurysm is small there may be insufficient arterio-venous shunt to cause cyanosis or clubbing, but it may yet rupture and bleed into the alveoli to cause recurrent haemoptysis. Under these circumstances diagnosis may be very difficult, 
and the patient may be suspected of pulmonary tuberculosis in spite of the failure to demonstrate tubercle bacilli in the sputum or from laryngeal swabs, and in spite of the atypical radiographic appearances. Lindgren's third patient, for example, was admitted to sanatorium on several occasions suspected of pulmonary tuberculosis. Once again tomograms may show the characteristic leash of vessels and establish the correct diagnosis, but when haemoptysis is an early symptom diagnosis may remain in doubt for months or years until, as the lesion gradually increases in size, cyanosis and polycythaemia develop.

GENESIS OF THE LESION.-The lesion is not a true tumour, but a developmental malformation (hamartoma). For this reason it would be better to discard the term haemangioma and call it simply an arterio-venous aneurysm. Although partly divided by septa, the lesion is essentially one cavity. The various compartments are the direct continuation of dilated veins and arteries, and the appearances suggest that the cavity is formed by the confluence of these vessels, the trabeculae and septa being persistent parts of the walls where fusion was incomplete. How fusion occurs, however, is a matter for speculation. There is widespread but irregularly distributed hypoplasia of the blood vessels, and it seems probable that fusion is due to aneurysmal dilation of hypoplastic veins and arteries at places where these happen to be contiguous. The diffuse hypoplasia of the dilated vessels entering and leaving the cavity is mainly, if not entirely, secondary to the increased flow through the shunt. But hypoplastic defects exist, both in the cavity itself and in the vessels elsewhere, which are primary. In many smaller arteries and veins the media is very attenuated, and often it is difficult to distinguish them except by their anatomical relations or continuity. The medial hypoplasia is sometimes accompanied by intimal thickening ( $a$ change which is more common in the venules), but in spite of this most of these small vessels are dilated.* The vascular hypoplasia affects also the larger vessels. In the arteries hypoplastic defects are found where vessels branch. These points of weakness show no thickening of the intima, but in spite of this they are not distended (probably because the pulmonary arterial blood pressure was low).

Some of the larger veins also are dilated. The

*Local hypoplastic defects of the pulmonary arteries were described by Gilmour and Evans (1946). These medial defects were compensated by intimal thickening which in the small arteries caused stenosis. They were found in normal subjects, but in one case which they described the stenoses were considered sufficiently numerous to be the main factor in the development of pulmonary hypertension. vein $\mathrm{X}$ in Case 2 (Plate XII $b$ ) was not only dilated, but elongated and kinked. The medial hypoplasia of this vein was compensated in most places by a fibro-elastic thickening of the intima, but in one part; proximal to the kink, the wall consisted of little more than endothelium. This remarkable vein was unlike the veins of chronic passive congestion, and although situated where hypostatic pressure was highest, there was no evidence that this was raised. No measurements of the pulmonary venous pressure were made, but had it been increased one would have expected that the alveoli where covered by endothelium would have been compressed, and there was no evidence of this. Compression was also sometimes absent where lung was similarly exposed in venous loculi of Case 1 (Plate $\mathrm{Xc}$ ). In the aneurysm, despite the distension, it still seems possible to recognize primary hypoplastic defects especially in the arteries (for example, the abrupt attenuation to a single elastic lamina of the artery in Plate IXa). In most of the venous loculi the walls show fibroelastic thickening; but, as in the vein $\mathrm{X}$, diśtension in places outran this compensatory process (Plate $\mathrm{X} a$ ). The arterio-venous aneurysm is progressive, enlargement apparently taking place by expansion (with compression of lung as in Plate $\mathrm{X} a$ ) ; and by disruption (with tearing of lung). Envelopment of bronchi (Plate $\mathrm{X} b$ ), and the formation of "Haff-like" venous loculi appear to be caused by disruption. These extensions of the lesion are probably associated more with the sudden venous distension, and other mechanical disturbances of coughing, than with the continuous pressure in the cavity, which is low. It may be that the initial intercommunication was brought about in the same way. That is, whilst the aneurysmal malformation was based on a vascular hypoplasia which was congenital, the arteriovenous intercommunication probably develops after birth.

TreatMent.-Arterio-venous aneurysms of the lung require surgical treatment in the form of pneumonectomy, lobectomy, or local excision. No medical measures will prevent the development of increasing dyspnoea, and serious complications may occur if surgery is not undertaken. Thus Bowers' (1936) patient died from rupture of the aneurysm. into the pleural cavity, Rodes's (1938) case from haemoptysis, and Alexander's (1945) second patient from coronary artery thrombosis for which the polycythaemia may have been responsible. Maier's (1948) patient developed infective endarteritis of the aneurysm, but was saved by penicillin therapy and lobectomy. 
Even in early cases, where there is but slight cyanosis and disability is minimal, operation should not be postponed on the chance that serial radiographs may show further aneurysms in the lungs and so modify operative technique. Maier and his colleagues emphasize that angiography may reveal other aneurysms too small to be made out on routine radiographs, and we consider now that this method of investigation, using 70 per cent diodone as the contrast medium, should be carried out on all these patients before operation. Aneurysms which cannot be made out radiologically can usually be seen beneath the pleura at thoracotomy and are always palpable, whilst early operation may allow local excision without sacrifice of the whole lobe. Small aneurysms can be excised from the lungs, as described by Janes (1944) by applying clamps around the aneurysm in such a way as to close its main supplying vessel last, thus allowing its expansile pulsation to demonstrate its outline. The cut edges of the lung can be closed by continuous through-and-through suture and the gap obliterated by apposition and suture of the edges. With large aneurysms a lobectomy must be performed, with dissection and ligature of the hilar structures; in our second case the middle lobe had to be sacrificed because of its common venous outflow with the lower lobe. The whole lung should be inspected and palpated to exclude other aneurysms.

The circulatory changes produced by removal of the aneurysm do not embarrass the patient, and no special measures such as venesection are needed either before or after operation. Cleland's (1948) patient died a few hours after lobectomy, possibly from heart failure, but the cause of death was not completely elucidated. The red cell count returns to normal within a few weeks, and the cyanosis lessens rapidly during the week after operation; in Jones and Thompson's (1944) patient it had disappeared, within a few hours.

Of the twenty-five examples of arterio-venous aneurysm of the lung on record medical treatment alone was employed for nine. Three of these patients died from the complications mentioned above ; the remaining six were alive at the time their case histories were reported, but four were disabled to some degree by dyspnoea.

Sixteen patients have been submitted to surgery. In one case (Watson, 1947) the feeder artery was ligated without excision of the aneurysm and the patient lost all his symptoms. In the cases reported by Janes (1944) and Lindgren (1946, second case) the aneurysms were multiple and were removed by local excision, and this method was also employed by Duvoir and his colleagues (1939); all three patients recovered. Seven patients have undergone lobectomy; four recovered and were cured of all symptoms, and three died-two from pulmonary embolism and staphylococcal septicaemia respectively, and a third for whose death no satisfactory cause could be found. Five patients have undergone pneumonectomy for pulmonary arterio-venous aneurysm and all have made a complete recovery.

\section{SUMMARY}

1. Two examples of arterio-venous aneurysm of the lung are reported.

2. The subject is reviewed, and the clinical picture described.

3. The pathological findings are recorded, and the genesis of the lesion discussed.

We are most grateful to Dr. Hewart Bell, who referred Case 1 to us. We are indebted to Prof. Wilfrid Newcomb for his interest and criticism, to Dr. S. A. Maddocks for the radiographs, and to Mr. W. Pereira for the photographs.

\section{REFERENCES}

Adams, W. E., Thornton, T. F., and Eichelberger, L. (1944). Arch. Surg., Chicago, 49, 51.

Alexander, W. S. (1945). N. Zealand med. J., 44, 180. Bowers, W. F. (1936). Nebraska med. J., 21, 55.

Cleland, W. P. (1948). Thorax, 3, 48.

Duvoir, M., Picot, G., Pollet, L., and Gaultier, M. (1939). Bull. Soc. med. Hop., Paris, 55, 596.

Gilmour, J. R., and Evans, W. (1946). J. Path. Bact., $58,687$.

Goldman, A. (1943). Diseases of the Chest, 9, 479.

Goldman, A. (1947). J. Lab. clin. Med., 32, 330.

Hepburn, J., and Dauphinee, J. A. (1942). Amer. J. med. Sci., 204, 681.

Hirsch, I. S. (1936). Radiology, 26, 469.

Janes, R. M. (1944). Brit. J. Surg., 31, 270.

Jones, J. C., and Thompson, W. P. (1944). J. thorac. Surg., 13, 357.

Lindgren, E. (1946). Acta radiol., Stockh., 27, 585.

Maier, H. C., Himmelstein, A., Riley, R. L., and Bunin, J. J. (1948). J. thorac. Surg., 17, 13.

Makler, P. T., and Zion, D. (1946). Amer. J. med. Sci., 211, 261.

Rodes, C. B. (1938). J. Amer. med. Ass., 110, 1914. Shenstone, N. S. (1942). J. thorac. Surg., 11, 405.

Smith, H. L., and Horton, B. T. (1939). Amer. Heart J., $18,589$.

Watson, W. L. (1947). Surgery, 22, 919.

Whitaker, W. (1947). Thorax, $2,58$. 